\title{
KAJIAN TEGANGAN-REGANGAN DAN KUAT TEKAN HVFA KADAR 50\% MEMADAT SENDIRI TERHADAP BETON NORMAL DENGAN KEKANGAN TEFLON DAN GREASE
}

\author{
Riswanda Binta Ichsan ${ }^{1)}$,Agus Setiya Budi ${ }^{2}$,Senot Sangadji ${ }^{3)}$ \\ 1)Mahasiswa Prodi Teknik Sipil, Fakultas Teknik, Universitas Sebelas Maret \\ 2),3) Pengajar Prodi Teknik Sipil, Fakultas Teknik, Universitas Sebelas Maret \\ Jl. Ir. Sutami 36A, Kenitngan Surakarta 57126; Telp 0271-634524 \\ Email: riswandabinta@gmail.com
}

\begin{abstract}
In some recent studies, there are new innovations by combining SCC-type concrete with high-grade fly ash. The innovation is known as High Volume Fly Ash-Self Compacting Concrete (HVFA-SCC). When testing concrete compressive strength using a compression test machine, friction forces occur on the upper and lower surfaces of the concrete. This has an effect on the stress-strain behavior in concrete. To reduce the friction force, the upper and lower surfaces of the concrete are given a medium to eliminate the friction force. In this research, we examine the effect of confinement in removing the friction force which occurs during compressive strength test with teflon and grease. From the stress-strain curve, the modulus of elasticity, ductility, poisson ratio, and toughness compared with the existing empirical formulas. This research method is an experiment with $50 \%$ of fly ash in the form of cylinders with $150 \mathrm{~mm} \times 300 \mathrm{~mm}$. Compressive strength test is done by Universal Machine Testing (UTM). From the results of the study it can be concluded that the average compressive strength by HVFA-SCC 50\% is 28,34 MPa and Normal Concrete is 26,31 MPa
\end{abstract}

Keywords: HVFA-SCC, stress and strain, restrain, teflon and grease

\begin{abstract}
Abstrak
Dalam beberapa penelitian terakhir, terdapat inovasi baru yaitu dengan menggabungkan beton yang berjenis scc dengan fly ash berkadar tinggi. Inovasi tersebut dikenal dengan High Volume Fly Ash -Self Compacting Concrete (HVFA-SCC). Pada saat pengujian kuat tekan beton dengan menggunakan mesin uji tekan, terjadi gaya friction pada permukaan atas dan bawah beton. Hal tersebut mengakibatkan pengaruh terhadap perilaku tegangan-regangan pada beton. Untuk mengurangi gaya friksi yang terjadi, pada permukaan atas dan bawah beton pada saat pengujian diberikan media yang bersifat menghilangkan gaya friksi. Dalam penelitian ini mengkaji pengaruh media untuk menghilangkan gaya friksi yang terjadi pada saat pengujian kuat desak yaitu dengan teflon dan grease. Metode penelitian ini adalah eksperimen dengan kadar fly ash $50 \%$ yang berbentuk silinder berukuran $150 \mathrm{~mm}$ x 300mm. Pengujian dilakukan dengan Universal Testing Machine (UTM). Dari hasil penelitian diperoleh kesimpulan rata-rata kuat desak yang dihasilkan oleh HVFA-SCC 50\% sebesar 28,35 MPa sedangkan Beton Normal sebesar $26,31 \mathrm{MPa}$.
\end{abstract}

Kata Kunci : HVFA-SCC,tegangan dan regangan,kekangan, teflon dan grease

\section{PENDAHULUAN}

Banyak peneliti mencari solusi permasalahan untuk mengurangi penggunaan semen yang tinggi. Salah satu alternative yang ada adalah penggunaan abu terbang (fly ash) sebagai bahan pengganti semen. Fly ash adalah sisa pembakaran batu bara yang dilakukan pada Pembangkit Listrik Tenaga Uap (PLTU) dan termasuk kedalam limbah berbahaya (B3). Fly ash sendiri dapat digunakan sebagai bahan pengganti semen karena fly ash bersifat pozzolan dan sebagai bahan filler. Di dalam fly ash sendiri memiliki kandungan silika dan alumina yang tinggi sehingga karakteristik yang dimiliki fly ash hampir sama dengan karakteristik pada semen. Dalam beberapa penelitian terakhir, terdapat inovasi baru yaitu dengan menggabungkan beton scc dengan fly ash dengan kadar yang tinggi. Inovasi tersebut dikenal dengan High Volume Fly Ash -Self Compacting Concrete (HVFA-SCC).

Beton yang mengalami gaya tekan tentunya menimbulkan tegangan (stress) di dalam beton. Tegangan ini menyebabkan bahan beton mengalami regangan (strain), sehingga perlu kiranya untuk mengetahui hubungan antara tegangan dan regangan pada beton. Hubungan antara tegangan regangan dapat ditampilkan dalam kurva grafik tegangan-regangan komplit. Pada saat pengujian kuat tekan beton dengan menggunakan mesin uji tekan, terjadi gaya friction pada permukaan atas dan bawah beton. Hal tersebut mengakibatkan pengaruh terhadap perilaku tegangan-regangan pada beton. Untuk mengurangi gaya friction yang terjadi, pada permukaan atas dan bawah beton pada saat pengujian diberikan media. Media yang digunakan adalah teflon dan grease.

Penelitian ini mengkaji mengenai Perilaku Tegangan-Regangan Beton HVFA-SCC (Kadar Fly Ash 50\%) Pada Pembebanan Uniaksial Tekan Dengan Kekangan Teflon dan Grease. Hasil dari penelitian adalah menganalisis perilaku tegangan-regangan yang terjadi pada beton HVFA-SCC dengan media teflon dan grease dan kemudian dibandingkan dengan beton normal. 


\section{TINJAUAN PUSTAKA}

High Volume Fly Ash - Self Compacting Concrete (HVFA-SCC) adalah kombinasi teknologi beton scc dengan menggunakan kadar Fly Ash yang tinggi. Syarat minimal beton HVFA adalah dengan mengganti semen dengan fly ash minimal $50 \%$ dari total binder.

Menurut ASTM C618-03, fly ash dapat dibedakan menjadi 3 jenis yang dapat dilihat pada tabel 1.

Tabel 1. Senyawa Kimia Fly Ash

\begin{tabular}{llll}
\multicolumn{1}{c}{ Senyawa Kimia } & \multicolumn{3}{c}{ Kelas } \\
\cline { 2 - 4 } & $\mathrm{N}$ & $\mathrm{F}$ & $\mathrm{C}$ \\
\hline $\begin{array}{l}\text { Oksida Silika }\left(\mathrm{SiO}_{2}\right)+\text { Oksida Alumina }\left(\mathrm{Al}_{2} \mathrm{O}_{3}\right)+\text { Oksida Besi } \\
\left(\mathrm{Fe}_{2} \mathrm{O}_{3}\right) \text {, minimum } \%\end{array}$ & 70 & 70 & 50 \\
\hline Trioksida Sulfur $\left(\mathrm{SO}_{3}\right)$, maksimum $\%$ & 4 & 5 & 5 \\
\hline Kadar air, maksimum $\%$ & 3 & 3 & 3 \\
\hline Kehilangan panas, maksimum $\%$ & 10 & 6 & 6
\end{tabular}

Penyusun fly ash sebagian besar terdiri dari silikat dioksida ( $\mathrm{SiO} 2)$, alumunium oksida (Al2O3), besi (Fe2O3), dan kalsium $(\mathrm{CaO})$, serta magnesium, pottasium, sodium, titanium, dan sulfur dalam jumlah yang lebih sedikit. Sebagian besar komposisi kimia dari fly ash tergantung berdasarkan jenis batu bara. Secara mekanis fly ash ini akan mengisi ruang kosong (rongga) diantara butiran- butiran dan secara kimiawi pemanfaatan fly ash yang memiliki kandungan silika ( $\mathrm{SiO} 2)$ yang tinggi memberikan kontribusi positif terhadap proses hidrasi semen, karena Silika akan mengikat $\mathrm{Ca}(\mathrm{OH}) 2$ untuk membentuk C-S-H gel yang membantu meningkatkan kekuatan beton (Solikin, 2012).

Selama uji desak, kontak antara pelat ujung logam dan spesimen beton menciptakan friksi di ujung beton, yang mempengaruhi perilaku tegangan-regangan beton. Dalam penggunaan pelat pengekang pada saat pengujian desak beton, friksi yang terjadi dapat diminimalisir sehingga keruntuhan beton yang terjadi lebih cepat dibandingkan dengan tanpa pengekang. Efek pengekangan pelat memiliki pengaruh yang besar pada kondisi beton postpeak.(Kumar et al.)

Tegangan adalah gaya persatuan luas penampang benda dan diberi notasi " $\sigma$ " (sigma). Secara matematis tegangan dapat dirumuskan dengan persamaan [1] :

$$
\sigma=\frac{P}{A} .
$$

Dimana:

$\sigma=$ Tegangan $(\mathrm{Mpa})$

$\mathrm{P}=$ Gaya $(\mathrm{N})$

$\mathrm{A}=$ Luas bidang tekan $\left(\mathrm{mm}^{2}\right)$

regangan yaitu perubahan relative ukuran atau bentuk benda yang mengalami tegangan dan diberi notasi " $\varepsilon$ ". Secara matematis regangan dapat di rumuskan dengan persamaan [2]:

$$
\varepsilon=\frac{\Delta l}{l_{0}} .
$$

Dimana:

$\varepsilon=$ Regangan

$\Delta l=$ Selisih panjang awal dan panjang akhir $(\mathrm{mm})$

$l_{0}=$ Panjang awal $(\mathrm{mm})$

\section{METODE}

Metode penelitian ini adalah eksperimen, dimana digunakan variasi kadar fly ash pada HVFA-SCC yaitu $50 \%$ serta beton normal sebagai pembanding. Sampel tersebut berbentuk silinder dengan ukuran $150 \mathrm{~mm}$ x $300 \mathrm{~mm}$. Untuk pengujian fly ash dengan uji XRF. Pada saat pengujian kuat desak menggunakan alat UTM kemudian kekangan yang digunakan adalah teflon dan grease .Dari sampel tersebut didapat karakteristik kurva tegangan-regangan beton HVFA-SCC yang dibandingkan dengan beton normal usia 28 hari. Untuk pengujian sifat SCC yaitu slump flow test, V-V unnel test, dan L-Box test. Standar SCC yang digunakan berdasarkan The European Guidelines for SelfCompacting Concrete (EFNARC) 2002. 


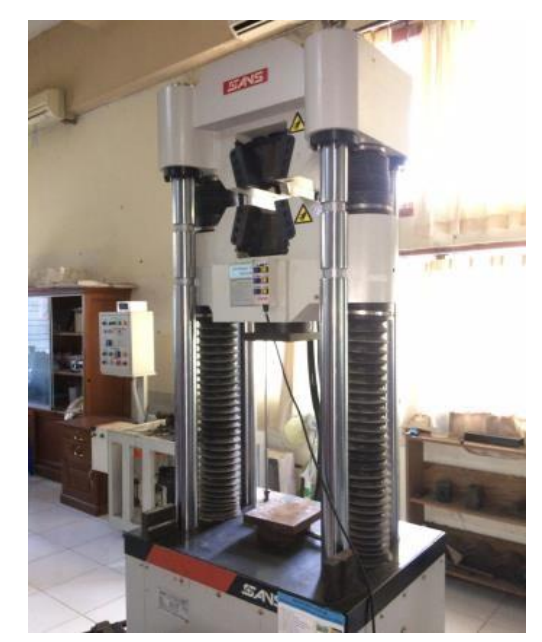

Gambar 1. Universal Testing Machine

\section{HASIL DAN PEMBAHASAN}

Mix Design

kebutuhan bahan adukan beton jenis High Volume Fly Ash - Self Compacting Concrete (HVFA-SCC) dan jenis Beton Normal untuk $1 \mathrm{~m} 3$ disajikan dalam table 2.

Tabel 2. Mix Design Untuk $1 \mathrm{~m} 3$

\begin{tabular}{ccccccc}
\hline Beton & $\begin{array}{c}\text { Agregat } \\
\text { Kasar } \\
\mathbf{( K g} / \mathbf{m} 3\end{array}$ & $\begin{array}{c}\text { Agregat } \\
\text { Halus } \\
\mathbf{( K g} / \mathbf{m} 3)\end{array}$ & $\begin{array}{c}\text { Semen } \\
\mathbf{( K g} / \mathbf{m} 3)\end{array}$ & $\begin{array}{c}\text { Fly Ash } \\
\mathbf{( K g} / \mathbf{m} 3)\end{array}$ & $\begin{array}{c}\text { Air } \\
(\mathbf{l t} / \mathbf{m} 3\end{array}$ & $\begin{array}{c}\text { Admixture } \\
\mathbf{( 1 t / m 3 )}\end{array}$ \\
\hline $\begin{array}{c}\text { HVFA- } \\
\text { SCC 50\% }\end{array}$ & 773,7 & 870,3 & 250 & 250 & 145 & 8 \\
\hline $\begin{array}{c}\text { Beton } \\
\text { Normal }\end{array}$ & 944,69 & 660,31 & 450 & - & 220 & - \\
\hline
\end{tabular}

\section{Hasil Pengujian Fly Ash}

Jumlah kandungan $\mathrm{Al}_{2} \mathrm{O}_{3}+\mathrm{SiO}_{2}+\mathrm{Fe}_{2} \mathrm{O}_{3}$ adalah sebesar 64,17\% dengan kandungan $\mathrm{Al}_{2} \mathrm{O}_{3}$ sebesar 11,29\%, $\mathrm{SiO}_{2}$ sebesar 31,76 \%, $\mathrm{Fe}_{2} \mathrm{O}_{3}$ sebesar 21,12\%. Sedangkan kadar $\mathrm{SO}_{3}$ sebesar 1,67\% dan $\mathrm{CaO}$ sebesar 15,02 \%. Sehingga menurut ASTM C-618 fly ash yang digunakan termasuk kedalam fly ash kelas C.

\section{Hasil Pengujian Sifat SCC}

Pengujian beton segar dilakukan sesuai aturan EFNARC 2002. "Specification and Guidelines for Self - Compacting Concrete". Pengujian Beton segar dilakukan dengan beberapa metode yaitu Slump Flow Test, L-Box Test, dan V-V unnel Test.

Pengujian slump flow test disajikan dalam table 3.

Tabel 3. Slump flow test

\begin{tabular}{ccccc}
\hline Kode & D1 $(\mathbf{m m})$ & D2 $(\mathbf{m m})$ & D rata-rata $(\mathbf{m m})$ & T 50 $(\mathbf{s})$ \\
\hline HVFA- & 700 & 700 & 700 & 3,16 \\
SCC 50\% & & & & \\
\hline
\end{tabular}

Pengujian L-Box test disajikan dalam table 4.

Tabel 4. L-Box test

\begin{tabular}{rccc}
\hline Kode & H1(mm) & H2 $(\mathbf{m m})$ & H2/h1 \\
\hline HVFA- & 85 & 90 & 0,94 \\
SCC $50 \%$ & & & \\
\hline
\end{tabular}

Pengujian $V$-V unnel test didapatkan hasil $\mathrm{t}=9,34 \mathrm{~s}$. Dari hasil pengujian sifat beton segar HVFA-SCC 50\% dapat disimpulkan bahwa memenuhi syarat berdasarkan standar EFNARC 2002. Pada pengujian beton normal nilai slump yang didapat adalah $12 \mathrm{~cm}$. Berdasarkan PBI 1971 nilai slump yang disyaratkan untuk beton normal adalah $7.5-15 \mathrm{~cm}$. Sehingga nilai slump memenuhi syarat. 


\section{Hasil Pengujian Kuat Desak Beton}

Pengujian kuat desak beton dilakukan pada saat benda uji berumur 28 hari menggunakan Universal Testing Machine (UTM) untuk mendapatkan beban maksimum ( $\mathrm{P}_{\text {maks }}$. Hasil pengujian disajikan dalam table 5.

Tabel 5. Hasil Kuat Desak HVFA-SCC 50\% dan Beton Normal

\begin{tabular}{cccc}
\hline Benda Uji & Luas $\left(\mathbf{m m}^{2}\right)$ & $\begin{array}{c}\text { Beban } \\
\text { Maks Rata- } \\
\text { Rata(N) }\end{array}$ & $\begin{array}{c}\text { Kuat Desak Rata- } \\
\text { Rata (Mpa) }\end{array}$ \\
\hline HVFA-SCC 50\% & 17671,46 & 500950 & 28,35 \\
\hline Beton Normal & 17671,46 & 464940 & 26,31 \\
\hline
\end{tabular}

Berdasarkan hasil pengujian kuat tekan HVFA-SCC 50\% dan Beton Normal didapatkan bahwa nilai rata-rata kuat desak HVFA-SCC 50\% sebesar 28,35 MPa dan Beton Normal sebesar 26,31 MPa. Dari hasil tersebut dapat dilihat bahwa penggunaan fly ash dapat meningkatkan kuat desak beton karena sifat fly ash sebagai filler. Sifat filler adalah dapat mengisi pori-pori yang kosong pada beton sehingga beton lebih padat. Berikut ditampilkan hasil rata rata kurva tegangan regangan HVFA-SCC $50 \%$ dan beton normal:

\section{KURVA TEGANGAN-REGANGAN HVFA-SCC 50\% DAN BETON NORMAL}

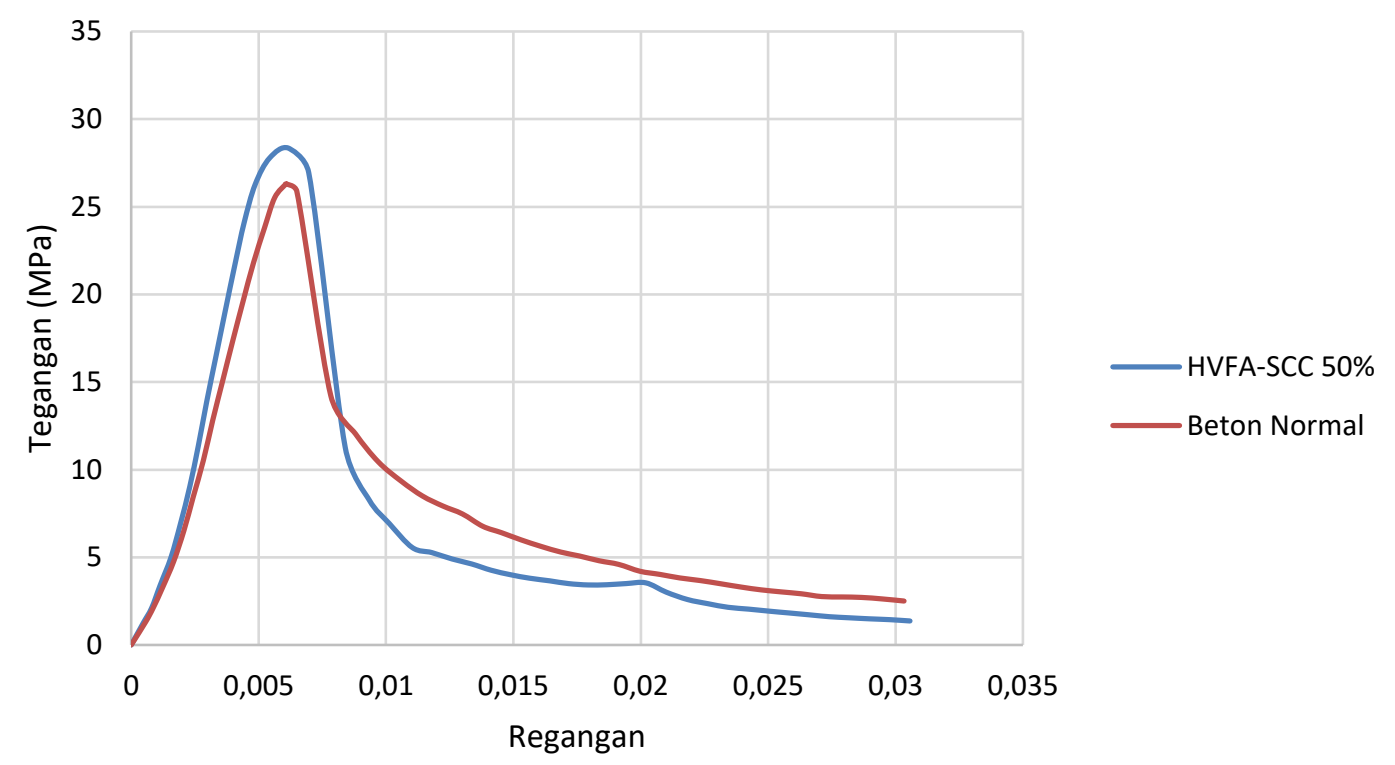

Gambar 2. Kurva Tegangan Regangan HVFA-SCC 50\% dan Beton Normal

Dari kurva tegangan-regangan di atas dapat dilihat bahwa karakteristik kurva tegangan regangan antara HVFASCC 50\% dengan beton normal relatif sama. Pada saat kondisi Pre-Peak tidak terjadi perbedaan yang signifikan Pada kondisi post peak untuk kurva beton normal menghasilkan kurva yang lebih landai dibandingkan dengan HVFA-SCC 50\%. Penggunaan fly ash pada kadar 50\% menunjukan bahwa karakteristik beton yang dihasilkan relatif sama dengan beton normal, sehingga penggunaan fly ash dengan kadar $50 \%$ sebebagai pengganti semen dapat diterapkan pada pengecoran beton struktural seperti pelat, kolom, dan balok. Dalam segi biaya dan lingkungan HVFA-SCC dalam penerapannya lebih menguntungkan dibandingkan dengan beton normal.

\section{KESIMPULAN}

Berdasarkan hasil pengujian dan analisis yang dilakukan, dapat diambil kesimpulan sebagai berikut:

1. Rata-rata kuat desak yang dihasilkan oleh HVFA-SCC $50 \%$ sebesar $27,38 \mathrm{MPa}$ sedangkan beton normal sebesar 24,07 MPa.

2. Penggunaan fly ash meningkatkan kuat desak dari beton karena fly ash bersifat filler. Dengan menggunakan fly ash dengan kadar 50\% akan mengurangi penggunaan semen sehingga mengurangi biaya produksi betun dan mengurangi efek rumah kaca yang ditimbulkan semen

\section{UCAPAN TERIMAKASIH}


Ucapan terimakasih penulis sampaikan kepada Bapak Agus Setiya Budi S.T, M.T dan Bapak Dr. Senot Sangadji, S.T, M.T. telah membimbing penulis dalam penelitian dan penyusunan ini. Terimakasih juga kepada Tim Gabungan Super dalam membantu pelaksanaan penelitian ini.

\section{REFERENSI}

Anonim. 2000. "SNI 03-1974-1990, "Metode pengujian kuat tekan beton". Badan Standarisasi Nasional, Jakarta ASTM C 618-03, 2003.Standard Specification for Pozzoland and Raw or Calcined Natural Pozzolan for Use in Concrete. United States:Association of Standard Testing Materials

EFNARC.2002."'Specification and Guidelines for Self-Compacting Concrete"

Anonim 1971.PB1-1971.’Peraturan Beton Bertulang Indonesia”.Yayasan Lembaga Penyelidikan Masalah Bangunan. Bandung.

S. Kumara, T. Mukhopadhyaya, S. A. Waseema, B. Singha, dan M. A. Iqbala. "Effect of platen restraint on stress-strain behaviour of concrete under uniaxial compression: A comparative study". Department of Civil Engineering, Indian Institute of Technology Roorkee, Roorkee, India.

Solikin, Mochamad. 2012. "Analisis Sifat Mekanis Beton Mutu Normal dengan Pemakaian Fly Ash sebagai pengganti Semen". Universitas Muhammadiyah Surakarta, Surakarta. 